\title{
Density Functional Theory Investigation of Some Pyridine Dicarboxylic Acids Derivatives as Corrosion Inhibitors
}

\author{
A. T. Hassan ${ }^{1}$, R.K. Hussein ${ }^{2 *}$, Mortaga Abou-krisha, ${ }^{3,4}$ and Mohamed I Attia ${ }^{3}$ \\ ${ }^{1}$ Department of Basic Science, October High institute of Engineering \& Technology - OHI, 2nd \\ neighbourhood. 3rd District. 6th of October, Giza, Egypt. \\ 2 Department of Physics, College of Science, Imam Mohammad Ibn Saud Islamic University (IMSIU), \\ Riyadh 11623, KSA. \\ ${ }^{3}$ Department of Chemistry, College of Science, Imam Mohammad Ibn Saud Islamic University \\ (IMSIU), Riyadh 11623, KSA. \\ ${ }^{4}$ Department of Chemistry, Faculty of Science, South Valley University, Qena, 83523, Egypt \\ *E-mail: eng rageh@yahoo.com
}

doi: $10.20964 / 2020.05 .11$

Received: 6 January 2020 / Accepted: 19 February 2020 / Published: 10 April 2020

The corrosion inhibition capability of four pyridine dicarboxylic acids was studied using the density functional theory (DFT) method at 6-311G (d, p) basis set. The molecular and electronic properties were investigated to distinguish the best adsorption efficiency on metal surface among the evaluated compounds, namely 2,3-Pyridine dicarboxylic acid, 2,4-Pyridinedicarboxylic acid, 2,5-Pyridine dicarboxylic acid, and 2,6-Pyridinedicarboxylic acid. The relationship between the quantum chemical parameters and inhibition efficiencies was recorded to remark the potential action as corrosion inhibitors. The results of the calculated reactivity parameters such as energy gap $(\Delta \mathrm{E})$, electronegativity $(\chi)$, electron affinity $(A)$, global hardness $(\eta)$, softness $(\sigma)$, ionization potential (I), the fraction of electrons transferred $(\Delta \mathrm{N})$, the electrophilicity $(\omega)$, molecular electrostatic potential, Mulliken charge, and optimized geometrical structure all supported the advantages of 2,3Pyridinedicarboxylic acid as a good inhibitor.

Keywords: Pyridine Dicarboxylic Acids; inhibition efficiency; DFT; quantum chemical parameters.

\section{FULL TEXT}

(C) 2020 The Authors. Published by ESG (www.electrochemsci.org). This article is an open access article distributed under the terms and conditions of the Creative Commons Attribution license (http://creativecommons.org/licenses/by/4.0/). 